\title{
Cholinergic receptor binding in unimpaired older adults, mild cognitive impairment, and Alzheimer's disease dementia
}

David L. Sultzer ${ }^{1,2^{*}}$, Aaron C. Lim ${ }^{1,3}$, Hailey L. Gordon ${ }^{1,4}$, Brandon C. Yarns ${ }^{1,5}$ and Rebecca J. Melrose $e^{1,5}$

\begin{abstract}
Background: Cholinergic neurotransmitter system dysfunction contributes to cognitive impairment in Alzheimer's disease and other syndromes. However, the specific cholinergic mechanisms and brain structures involved, time course of alterations, and relationships with specific cognitive deficits are not well understood.

Methods: This study included 102 older adults: 42 cognitively unimpaired (CU), 28 with mild cognitive impairment $(\mathrm{MCl})$, and 32 with Alzheimer's disease (AD) dementia. Each participant underwent a neuropsychological assessment. Regional brain a4 $\beta 2$ nicotinic cholinergic receptor binding $\left(V_{T} / f p\right)$ was measured using 2- $\left[{ }^{18} \mathrm{~F}\right]$ fluoro-3-(2(S)azetidinylmethoxy)pyridine (2FA) and PET imaging. Voxel-wise analyses of group differences were performed. Relationships between receptor binding and cognition, age, and cholinesterase inhibitor medication use were assessed using binding values in six prespecified regions of interest.
\end{abstract}

Results: SPM analysis showed the group $V_{T} / f_{p}$ binding differences in the bilateral entorhinal cortex, hippocampus, insula, anterior cingulate, thalamus, and basal ganglia ( $p<.05$, FWE-corrected). Pairwise comparisons revealed lower binding in the AD group compared to the $\mathrm{CU}$ group in similar regions. Binding in the entorhinal cortex was lower in the $\mathrm{MCl}$ group than in the $\mathrm{CU}$ group; binding in the hippocampus was lower in the $\mathrm{AD}$ group than in the $\mathrm{MCl}$ group. AD participants taking cholinesterase inhibitor medication had lower 2FA binding in the bilateral hippocampus and thalamus compared to those not taking medication. In the CU group, age was negatively associated with $2 F A$ binding in each region of interest $\left(r_{s}=-.33\right.$ to $-.59, p<.05$ for each, uncorrected). Attention, immediate recall, and delayed recall scores were inversely associated with 2 FA binding in most regions across the full sample. In the combined group of $\mathrm{CU}$ and $\mathrm{MCl}$ participants, attention was inversely associated with 2FA binding in most regions, beyond the effect of hippocampal volume.

Conclusions: Nicotinic cholinergic receptor binding in specific limbic and subcortical regions is lower in $\mathrm{MCl}$ and further reduced in AD dementia, compared to CU older adults, and is related to cognitive deficits. Cognitive decline with age may be a consequence of reduced cholinergic receptor density or binding affinity that may also promote vulnerability to other Alzheimer's processes. Contemporary modification of the "cholinergic deficit" of aging and AD may reveal opportunities to prevent or improve clinical symptoms.

Keywords: Cholinergic receptors, Mild cognitive impairment, Alzheimer's disease, Cognitive aging

\footnotetext{
*Correspondence: dsultzer@uci.edu

${ }^{2}$ Department of Psychiatry and Human Behavior, School of Medicine,

and Institute for Memory Impairments and Neurological Disorders (UCI

MIND), University of California, Irvine, Irvine, CA, USA

Full list of author information is available at the end of the article
}

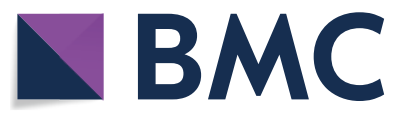

(c) The Author(s) 2022. Open Access This article is licensed under a Creative Commons Attribution 4.0 International License, which permits use, sharing, adaptation, distribution and reproduction in any medium or format, as long as you give appropriate credit to the original author(s) and the source, provide a link to the Creative Commons licence, and indicate if changes were made. The images or other third party material in this article are included in the article's Creative Commons licence, unless indicated otherwise in a credit line to the material. If material is not included in the article's Creative Commons licence and your intended use is not permitted by statutory regulation or exceeds the permitted use, you will need to obtain permission directly from the copyright holder. To view a copy of this licence, visit http://creativecommons.org/licenses/by/4.0/. The Creative Commons Public Domain Dedication waiver (http://creativeco mmons.org/publicdomain/zero/1.0/) applies to the data made available in this article, unless otherwise stated in a credit line to the data. 


\section{Introduction}

Acetylcholine neurotransmitter system dysfunction has been observed across the continuum from cognitive aging to mild cognitive impairment (MCI) and Alzheimer's disease (AD) [1-6]. Beginning in the 1970s, AD has been associated with a loss of cholinergic neurons in the nucleus basalis of Meynert and their broad cortical projections $[7,8]$, as well as choline acetyltransferase decline in the cortex [9].

More recent studies indicate that atrophy of basal forebrain cholinergic neurons occurs with normal aging and accelerates after age 65 years, with further volume loss in early AD dementia [10]. Importantly, cholinergic receptors in the hippocampus and entorhinal cortex that modulate cellular, synaptic, and network activity in learning and memory processes are particularly susceptible to afferent cholinergic loss [11-13]. Further support for the role of the cholinergic system in cognition comes from observations that cholinergic antagonists worsen attention and memory, whereas pro-cholinergic treatments provide modest symptomatic improvement in patients with AD dementia [6, 14].

Relationships between cholinergic system dysfunction and other AD pathologies are complex and bidirectional. For example, cholinergic receptors may be adversely affected by beta amyloid peptides [15], but cholinergic neurotransmission also influences amyloid processing $[16,17]$ and may protect neurons from amyloid toxicity $[18,19]$. Tau pathology is prominent in the basal forebrain early in the AD process [4] and may initiate distant cortical degeneration [12, 20]. There are additional complex links between cholinergic system dysfunction and tau processing [21-23], neuroinflammation [18, $24]$, cortical volume loss $[25,26]$, and apolipoprotein $E$ $\varepsilon 4$-mediated neuronal alterations in the medial temporal cortex [27]. Cholinergic receptor activity also modulates other neurotransmitter systems and may support synaptic integrity via the glutamatergic pathway in the hippocampus [28]. However, despite major recent advances in understanding the cellular and molecular events in $\mathrm{AD}$, the sequence of evolving pathophysiologies, relationships with clinical symptoms, and value as therapeutic targets are incompletely understood. Whether cholinergic system dysfunction occurs early, late, or across the continuum from cognitive aging to $\mathrm{AD}$ remains unclear $[3,6,22]$.

Evaluating cholinergic neurotransmission in vivo in cognitive aging and $\mathrm{AD}$ can improve the understanding of $\mathrm{AD}$ pathophysiology, reveal the role of cholinergic dysfunction in the cascade, and identify treatment targets or biomarkers for treatment response. Relationships between cholinergic dysfunction and cognitive impairment seen in previous studies suggest that cholinergic interventions may help to improve clinical symptoms as well as ameliorate the toxic neurodegenerative cascade. Neuroimaging with cholinergic receptor ligands has been used to measure receptor binding in AD and links to cognitive abilities [29-34]. Our group used 2-[18F]fluoro-3-(2(S)azetidinylmethoxy)pyridine (2FA) and positron emission tomography [35-37] to measure $\alpha 4 \beta 2$ nicotinic cholinergic receptors (nAChR) in vivo in $A D$ [38]. In our study, 2FA binding was lower in the medial temporal cortex, anterior cingulate, insula/ opercula, medial thalamus, inferior caudate, and brainstem in patients with mild to moderate AD compared to cognitively unimpaired older adults, although binding was not associated with cognition in the AD participants. However, across the studies to date, sample sizes have been relatively small, results have varied, and few have evaluated cholinergic receptor binding across the spectrum of aging, $\mathrm{MCI}$, and clinical $\mathrm{AD}$.

The current cross-sectional study used 2FA PET imaging to measure nicotinic receptor binding in cognitively unimpaired older adults and individuals with $\mathrm{MCI}$ and $\mathrm{AD}$ dementia. The goal of the study was to compare the regional binding profiles across this continuum, with particular attention to binding in the medial temporal cortex where alterations may have prominent cognitive consequences. A second goal was to assess the relationships between regional nAChR binding and attention, concentration, and memory skills.

\section{Materials and methods \\ Participants}

Study participants $(n=102)$ included cognitively unimpaired older adults (CU; $n=42)$, individuals with $\mathrm{MCI}$ $(n=28)$, and those with AD dementia $(n=32)$. A subset of participants (CU: $n=22$; AD: $n=24$ ) was included in a prior study by our group [38]. Participants were recruited from VA Greater Los Angeles Healthcare System (VAGLAHS) specialty clinics that assess or treat memory disorders, as well as primary care sites. Additional participants were recruited from community programs. All participants were age 60 years or older. The exclusion criteria included the following: history of tobacco use in the past 10 years, history of head trauma with loss of consciousness for more than $30 \mathrm{~min}$, a history of neurological disorder such as seizure disorder, movement disorder, or stroke, and a history of primary psychotic disorder or bipolar disorder. Individuals currently taking antidepressants $(n=27)$, cholinesterase inhibitor medication (AChEI; $n=32)$, or memantine $(n=20)$ at a stable dosage for at least 3 months were eligible for the study. Those taking other psychotropic medications were excluded. 


\section{Study procedures}

All participants underwent a research clinical assessment that included medical history interview, review of cognitive symptoms and functional abilities, review of prior clinical neuroimaging studies, and neuropsychological assessment. The results were reviewed by two neuropsychologists to confirm study eligibility and to assign a diagnostic group (CU, MCI, or AD). Neuropsychological test scores (see below) were converted to $z$-scores based on published norms. Performance within each cognitive domain was assessed. If a participant scored at least 1.5 standard deviations below the adjusted norm on two or more tests, the domain was rated as impaired. Estimates of premorbid functioning were considered when making these determinations. The ability to perform instrumental activities of daily living (IADLs) was evaluated using the Lawton and Brody IADL assessment [39] and medical records. Individuals were rated as $\mathrm{CU}$ if all cognitive domains showed no impairment and IADLs were performed independently. MCI included those with cognitive impairment in the memory domain and intact IADLs. Participants were diagnosed with probable AD according to the NIA/AA criteria [40] if there was an impairment in at least two cognitive domains (one of which had to be memory) detected through a combination of patient/informant report and objective assessment, insidious symptom onset, and IADL dependence. Amyloid status was not assessed, and the $\mathrm{A} / \mathrm{T} / \mathrm{N}$ classification system was not applied [41]. Following the research assessment, additional exclusion criteria applied to all participants included the following: history or exam suggestive of an alternative dementia diagnosis, evidence of stroke or moderate/severe cerebrovascular disease on structural imaging, or systemic illness, neurologic illness, or medication that could explain the cognitive decline.

\section{Neuropsychological assessments}

The Mini-Mental State Exam (MMSE) and Mattis Dementia Rating Scale were used to assess global cognition. Simple attention was evaluated with the Trails A test and Digit Span. Verbal memory was assessed using the Logical Memory (LM) subtest of the Weschler Memory Scale-Revised and the immediate and delayed free recall tasks of the Consortium to Establish a Registry for Alzheimer's Disease (CERAD) word-list memory test. Visuospatial memory was assessed using the Brief Visuospatial Memory Test-Revised (BVMT-R) and the recall condition of the Rey-Osterrieth (Rey O) Complex Figure task.

Three average scores were generated: (1) an average attention score (ATT) was generated by averaging $z$-scores from the Stroop Word Reading, Stroop Color
Naming, and Trails A tasks; (2) an average immediate recall (IR) score was generated by averaging across the three learning-trials $z$-scores in the CERAD, BVMT-R, and Logical Memory I tests; and (3) an average delayed recall (DR) score was established by averaging across $z$-scores from the CERAD delayed memory, BVMT-R delayed recall, Rey-O delayed recall, and Logical Memory II tests.

\section{Magnetic resonance imaging (MRI)}

We obtained structural brain MR images using a fast 3D-MPRAGE sequence (T1; TR, 2000; TE, 2.59; TI, 900; slice thickness $1.0 \mathrm{~mm}$ ) on a 1.5-T Magnetom Symphony System scanner (Siemens, Washington, DC). The images were used to help define anatomic regions and to generate gray matter maps for use in the 2FA PET imaging analyses. Hippocampal volume, proportional to intracranial cavity volume, was calculated for each participant using FreeSurfer (http://surfer.nmr.mgh.harvard.edu/) [42].

\section{FA PET imaging}

The 2FA radiotracer utilized in this study was prepared at the VAGLAHS Cyclotron Facility [43]. Procedures for the radiotracer synthesis and infusion, image acquisition, and plasma analyses have been described previously [35, 44]. Briefly, study participants received an initial intravenous bolus infusion of $143.6(\mathrm{SD}=12.6) \mathrm{MBq} 2 \mathrm{FA}$ in $5 \mathrm{~mL}$ saline, followed by a continuous slow infusion of 145.8 $(\mathrm{SD}=8.0) \mathrm{MBq} 2 \mathrm{FA}$ over the following 3-h tracer uptake and 1-h PET imaging periods. This procedure maintains a stable 2FA level in the brain tissues during PET image acquisition $[35,45,46]$.

PET images were acquired using the Gemini TF PETCT scanner (Philips, Amsterdam, The Netherlands) in three-dimensional mode. Total scan time was $60 \mathrm{~min}$, and images were reconstructed in 1-min frames using a three-dimensional reconstruction algorithm and Gaussian filtered back projection with a kernel of $8 \mathrm{~mm}$ full width at half maximum (FWHM).

\section{Venous plasma assay}

Blood samples were collected at the start of PET image acquisition and at 15-min intervals during the 60-min PET acquisition period. Parent (non-metabolized) 2FA in the blood plasma samples was measured using solidphase extraction [47], and the proportion of unbound 2FA in the plasma was measured after ultrafiltration [48]. 2FA binding volume of distribution $\left(V_{T} / f_{p}\right)$ on PET images was calculated using the values of parent and unbound 2FA activity in the plasma. This method accounts for inter-participant variability in radiotracer 
metabolism and protein binding. $V_{T} / f_{p}$ approximates nicotinic receptor binding potential and is proportional to $B_{\max } / K_{d}[49]$.

\section{PET image processing}

2FA PET images were processed and analyzed using SPM12. The 60 1-min frames were motion-corrected and then averaged to create one mean subject-level image. Counts within the image voxels were converted to $V_{T} / f_{p}$ values by dividing the voxel activity by the activity of parent and unbound 2FA activity in plasma.

\section{PET image processing and partial volume adjustment}

Due to the age of participants and potential cortical atrophy, partial volume correction was applied to the PET images using PETPVE from the SPM Toolbox to normalize 2FA grey matter activity [50]. PETPVE outputs two types of data available for analysis: voxel-wise images (PVE-c) [51] and region-of-interest-based data using a geometric transfer matrix method (PVEc-GTM) [52]. First, MRI and 2FA PET images were co-registered, and MRI images were segmented into white matter (WM), gray matter (GM), and cerebrospinal fluid (CSF) components using the VBM8 toolbox [53]. GM voxels were then spatially weighted as the true value of radioactive isotope uptake. These weighted values were then compared to WM and CSF spatial values, based on the point spread function of the PET tomograph. The three weighted values were used to correct for spill-over of activity in the GM and surrounding tissue [50]. PET images were normalized to MNI space, yielding a 2FA PET image in MNI space that had been corrected for partial volume effects. These images were subsequently smoothed using an 8-mm FWHM kernel and used in subsequent voxelbased analyses.

In the second arm of PETPVE, PVEc-GTM, an MNI space region-of-interest (ROI) atlas (Desikan-Killiany [54]) was manipulated into the participant's brain space. The atlas was then limited to GM-corrected segmented tissue. The mean voxel 2FA activity was then extracted from six bilateral anatomical ROIs that had shown CU-AD group differences in a prior study [38]: entorhinal cortex, hippocampus, insula, anterior cingulate, thalamus, and caudate (core ROIs). The mean 2FA $V_{T} / f_{p}$ in the six core ROIs were used in subsequent ROI analyses.

\section{Statistical analyses}

2FA binding differences in the $\mathrm{CU}, \mathrm{MCI}$, and $\mathrm{AD}$ groups were first compared using a one-way ANOVA in SPM12. The groups were modeled assuming independence and unequal variance, thresholding was used to remove spurious 2FA signal, and implicit masking was applied. The main effects were assessed using a voxel-level significance of $p<.05$ corrected using the familywise error procedure (FWE). Planned post hoc tests compared 2FA binding pairwise between the groups at $p<.05$, FWE-corrected. In addition, we used small volume correction to assess the differences in the medial temporal lobe structures, specifically the bilateral entorhinal cortex and hippocampus. A mask of the bilateral entorhinal and hippocampal regions was created using the neuromorphetrics atlas in SPM (neuromorphometrics.com). Findings within the mask were assessed at the voxel level, $p<.05$, FWE-corrected.

Region-of-interest (ROI) analyses were also conducted to assess the 2FA binding differences among the diagnostic groups in specific anatomical regions. Atrophy-corrected $V_{T} / f_{p}$ values were extracted from the six bilateral core ROIs. ROI group analyses were conducted using MANOVAs in SPSS v25, with 2FA binding in each region as the dependent variables and group as the independent variable. Bonferroni-corrected post hoc tests explored the pairwise group differences in those regions with a significant overall group effect.

Multiple tests were conducted to ensure that assumptions for MANOVA analyses were met. Mahalanobis distance was calculated to detect multivariate outliers, and one case was removed from further analysis. The Shapiro-Wilks tests were used to examine the normality of each dependent variable for each diagnostic group $(p=.09-.98)$. Box's $M$ test was calculated to assess the equality of covariance (Box's $M=224.50, p=.07$ ). A priori power calculation for MANOVA indicated a required total sample of 81 to detect an effect size (f2V) of .16 with $80 \%$ power, with alpha set at $.05,3$ total groups, and 12 response variables. A priori power calculation for correlational analyses indicated a required total sample of 82 to detect an effect size of 0.3 with $80 \%$ power, with alpha set at .05 using a two-tailed test. Power calculations were carried out using GPower 3.1.7 [55].

\section{Results}

Sample characteristics and clinical assessment scores for participants in the $\mathrm{CU}, \mathrm{MCI}$, and $\mathrm{AD}$ diagnostic groups are shown in Table 1. The mean MMSE scores were 27.3 and 19.8 in the MCI and $\mathrm{AD}$ groups, respectively. The groups were not significantly different in the distribution of race or years of education. There was a significant difference in age and sex, such that those in the $\mathrm{AD}$ group were older and more likely to be male than those in the MCI and CU groups $(p \mathrm{~s}<.02)$. Overall, there was a high proportion of male participants in the sample, as the study primarily recruited veterans. $\mathrm{AD}$ participants had received this diagnosis an average of 4.8 years (SD 3.44; range $<1$ to 14 years) prior to the time of the 2FA scan. 
Table 1 Participant characteristics

\begin{tabular}{|c|c|c|c|c|}
\hline & $\begin{array}{l}\text { Cognitively } \\
\text { unimpaired }(n=42)\end{array}$ & $\begin{array}{l}\text { Mild cognitive } \\
\text { impairment }(n=28)\end{array}$ & $\begin{array}{l}\text { Alzheimer's disease } \\
(n=32)\end{array}$ & Statistics \\
\hline Male/female & $28 / 14$ & $24 / 4$ & $32 / 0$ & Fisher's exact test, $p<.001$ \\
\hline Age, years & $72.1(7.5)$ & $74.6(8.5)$ & $79.4(7.6)$ & $F(2,99)=7.97, p=.001$ \\
\hline Education, years & $16.1(2.7)$ & $15.4(2.5)$ & $14.8(3.5)$ & $F(2,98)=1.64, p=.20$ \\
\hline Race/ethnicity, n & & & & Fisher's exact test, $p=.75$ \\
\hline African-American & 9 & 8 & 9 & \\
\hline White, non-Hispanic & 30 & 16 & 21 & \\
\hline Hispanic & 2 & 2 & 2 & \\
\hline Asian American/Pacific Islander & 1 & 2 & 0 & \\
\hline Duration of dementia, years & - & - & $4.8(3.4)$ & \\
\hline MMSE & $29.3(1.1)$ & $27.3(1.9)$ & $19.8(5.0)$ & $F(2,99)=93.06, p<.001$ \\
\hline Dementia Rating Scale total & $140.0(3.65)$ & $133.1(7.6)$ & $104.5(24.0)$ & $F(2,97)=60.30, p<.001$ \\
\hline \multicolumn{5}{|l|}{ Current medications, $n(\%)$} \\
\hline Cholinesterase inhibitor & $1(2 \%)$ & $8(29 \%)$ & $23(72 \%)$ & Fisher's exact test, $p<.001$ \\
\hline Memantine & $0(0 \%)$ & $3(11 \%)$ & $17(53 \%)$ & Fisher's exact test, $p<.001$ \\
\hline Antidepressant & $6(14 \%)$ & $9(32 \%)$ & $12(38 \%)$ & Fisher's exact test, $p<.001$ \\
\hline Trails A, s & $39.5(12.2)$ & $48.3(16.7)$ & $102.6(62.0)$ & $F(2,92)=28.62, p<.001$ \\
\hline Attention average Z-score & $-.80(.61)$ & $-1.36(.61)$ & $-2.37(1.19)$ & $F(2,92)=29.25, p<.001$ \\
\hline Immediate Memory average Z-score & $-.16(.62)$ & $-1.30(.75)$ & $-2.30(.52)$ & $F(2,92)=40.99, p<.001$ \\
\hline Delayed Memory average Z-score & $.10(.64)$ & $-1.50(.63)$ & $-2.49(.44)$ & $F(2,92)=102.84, p<.001$ \\
\hline Hippocampal volume (\% of whole brain) & $.0050(.0006)$ & $.0046(.0007)$ & $.0038(.0006)$ & $F(2,95)=30.54, p<.001$ \\
\hline
\end{tabular}

Means (SD) are shown for continuous variables; proportions and percentages are shown for sex, race, and current medications. One-way ANOVAs and Fisher's exact tests were used to compare the groups. Sample sizes for the AD group were smaller for some comparisons because of the inability of some AD patients to complete the measure

\section{FA binding among the diagnostic groups Voxel-based analysis (SPM)}

The overall ANOVA of 2FA binding among the three diagnostic groups showed an effect of diagnosis on binding in the bilateral entorhinal cortex, hippocampus, insula, anterior cingulate, thalamus (anterior, ventral anterior, and dorsomedial nuclei), and basal ganglia (including bilateral caudate and anterior putamen) (Fig. 1, Table 2). An independent samples $t$-test showed that AD participants had lower 2FA binding than $\mathrm{CU}$ participants in most of the same regions identified in the overall ANOVA (Fig. 2A). Pairwise comparisons also showed that AD participants had lower 2FA binding in the bilateral hippocampus compared to those with $\mathrm{MCI}$ (Fig. 2B, Table 3). There were no voxel clusters with binding differences between the MCI and CU groups at the prespecified statistical level when the search volume included the whole brain. However, the results using the small volume correction showed lower binding in the bilateral entorhinal cortex in MCI compared to $\mathrm{CU}$ (Fig. 2C; Table 3). There were no voxel clusters in which AD participants showed significantly greater binding than those in the CU or MCI groups. There were also no voxel clusters in which MCI participants showed significantly greater binding than those in the CU group.

\section{ROI analysis}

The mean 2FA binding in the six core ROIs (bilateral hippocampus, entorhinal cortex, insula, anterior cingulate, thalamus, and caudate) in the three diagnostic groups are shown in Fig. 3. There was an overall effect of the diagnostic group on all six ROIs $(F(2,99)=3.4-15.2$, $p s=.000002-.038)$. In post hoc pairwise comparisons, participants with $\mathrm{AD}$ had lower 2FA binding than those in the CU group in all ROIs, bilaterally ( $p s=.00002-.034$, Bonferroni-corrected; $n=32$ for $\mathrm{AD}, n=42$ for $\mathrm{CU}$ ). $2 \mathrm{FA}$ binding in the $\mathrm{AD}$ group was also lower than that in the MCI group in the bilateral hippocampus. 2FA binding in the MCI group was lower than that in the CU group in the left entorhinal cortex, bilateral insula, and left anterior cingulate.

\section{Effect of medication treatment on 2FA binding}

Twenty-three of $32 \mathrm{AD}$ participants and eight of $28 \mathrm{MCI}$ participants were taking a stable dose of AChEI medication at the time of 2FA PET imaging. 2FA binding in the six core ROIs among those taking AChEI medication was compared to those not taking AChEI medication within the AD and MCI groups individually (Table 4). In the AD group, 2FA binding in those taking AChEI medication was lower in the bilateral thalamus and hippocampus 

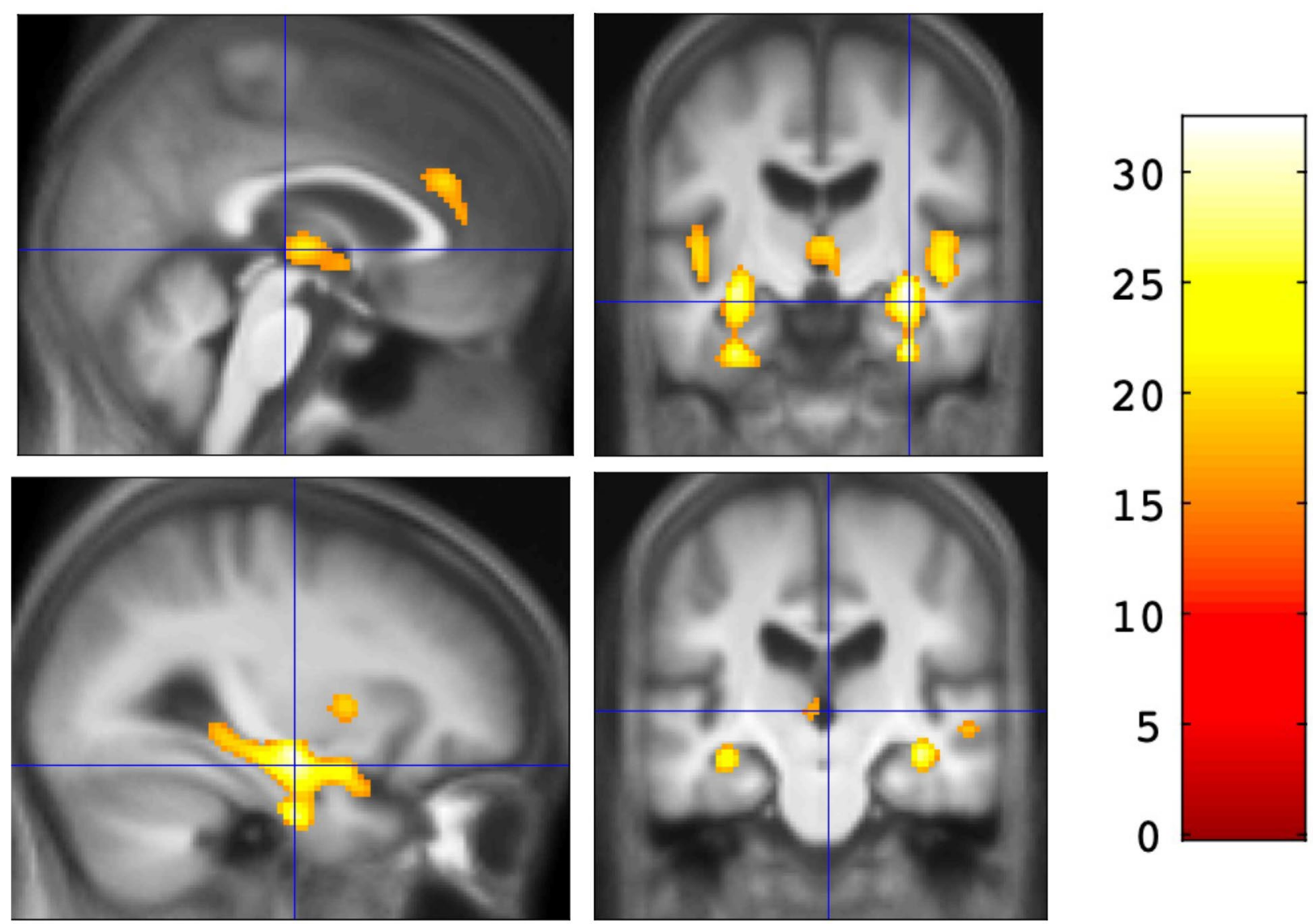

Fig. 1 Results of the overall ANOVA showing the effect of diagnosis on 2FA binding $\left(V_{T} / f_{p}\right.$ values, $p<.05$, FWE-corrected at the voxel level). F-score is shown on the color scale

Table 2 Overall voxel-wise ANOVA showing the main effects of diagnosis on 2FA binding $\left(V_{T} / f_{p}\right)$

\begin{tabular}{lllll}
\hline Regions & $\boldsymbol{K}$ & $\boldsymbol{P}_{\text {FWE-corr }}$ & $\boldsymbol{F}$ Statistic & Coordinates \\
\hline $\begin{array}{l}\text { R thalamus, R hip- } \\
\text { pocampus, R entorhinal } \\
\text { cortex, R insula, R } \\
\text { caudate, R putamen }\end{array}$ & 2923 & 0 & 32.28 & {$[30,-10,-14]$} \\
$\begin{array}{l}\text { L thalamus, L hip- } \\
\text { pocampus, L entorhi- } \\
\text { nal cortex, L insula, } \\
\text { caudate, L putamen }\end{array}$ & 2127 & 0 & 28.56 & {$[-30,-14,-12]$} \\
$\begin{array}{l}\text { Bilateral anterior } \\
\text { cingulate }\end{array}$ & 75 & 0.003 & 19.46 & {$[2,34,26]$} \\
$\begin{array}{l}\text { R middle temporal } \\
\text { gyrus }\end{array}$ & 21 & 0.006 & 18.62 & {$[50,-24,-4]$} \\
\hline
\end{tabular}

Findings are significant at the voxel level at $p<.05$ FWE-corrected. $K=$ number of voxels. Coordinates referenced to MNI space compared to those not taking AChEI medication. In the MCI group, there were no significant differences between those on and off AChEI medications in any ROI.

When the MANOVA of 2FA binding in ROIs across the groups included AChEI medication use as a covariate in the model, participants with AD had lower binding in the bilateral hippocampus, left entorhinal cortex, bilateral insula, and left caudate, compared to the $\mathrm{CU}$ group (post hoc pairwise comparisons, $p s=.003-.037$, Bonferroni-corrected; $n=32$ for $\mathrm{AD}, n=42$ for $\mathrm{CU}$ ). Participants with MCI had lower binding in the left entorhinal cortex, bilateral insula, and left anterior cingulate, compared to the CU group (post hoc pairwise comparisons, $p s=.003-.046$, Bonferroni-corrected; $n=28$ for $\mathrm{MCI}, n=42$ for $\mathrm{CU})$. There were no significant 2FA binding differences between the $\mathrm{AD}$ and $\mathrm{MCI}$ groups for any region in this model.

We also separately examined the effect of stable memantine treatment on 2FA binding in the AD group. There was no significant binding difference between 


\section{A) $\mathrm{CU}>\mathrm{AD}$}
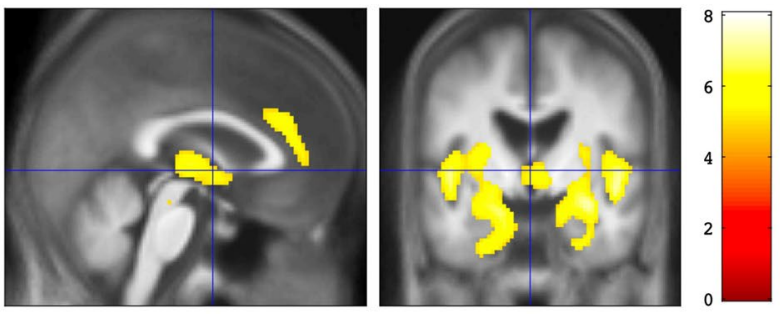

B) $\mathrm{MCI}>\mathrm{AD}$
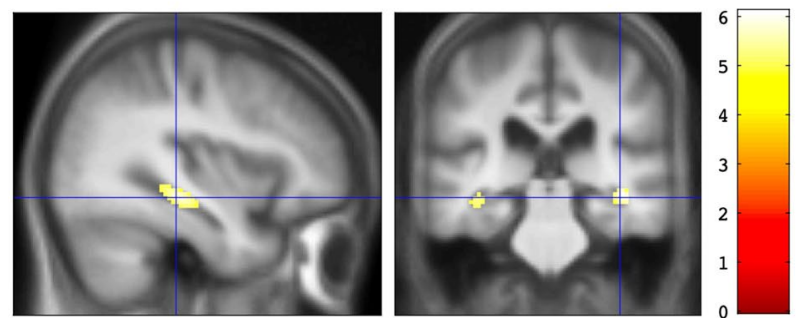

C) $\mathrm{CU}>\mathrm{MCI}$, small volume corrected
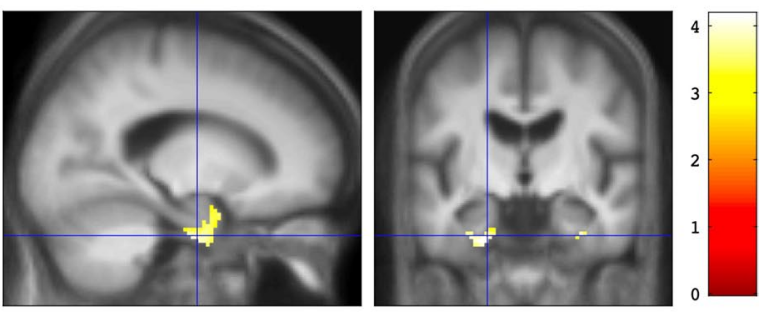

Fig. 2 SPM maps of pairwise comparisons of 2FA binding ( $V_{T} / f_{p}$ values). T-score is shown on the color scale. For $C U>A D(A)$ and $M C l>A D(B)$, the results are shown across the entire brain $(p<.05$, FWE-corrected at the voxel level). For $\mathrm{CU}>\mathrm{MCI}(\mathbf{C})$, the results are shown within the bilateral hippocampal/entorhinal mask ( $p<.05$, FWE-corrected using small volume correction)

Table 3 Pairwise comparisons of 2FA binding $\left(V_{T} / f_{p}\right)$ between the diagnostic groups, voxel-wise analysis

\begin{tabular}{|c|c|c|c|c|}
\hline Regions & $K$ & $P_{\text {FWE-corr }}$ & $T$ statistic & Coordinates \\
\hline \multicolumn{5}{|l|}{$C U>A D$} \\
\hline $\begin{array}{l}\text { Bilateral hippocampus, temporal pole, insula, cau- } \\
\text { date, putamen, thalamus }\end{array}$ & 9285 & 0 & 8.03 & {$[30,-10,-12]$} \\
\hline Bilateral anterior cingulate & 238 & 0 & 6.2 & {$[2,34,26]$} \\
\hline Right temporal pole & 44 & 0.003 & 5.64 & {$[28,18,-44]$} \\
\hline Left calcarine fissure & 34 & 0.005 & 5.49 & {$[-14,-62,8]$} \\
\hline \multicolumn{5}{|l|}{$\mathrm{MCl}>\mathrm{AD}$} \\
\hline Right hippocampus & 143 & 0 & 6.09 & {$[40,-34,-6]$} \\
\hline Left hippocampus & 69 & 0.001 & 5.84 & {$[-36,-34,-6]$} \\
\hline \multicolumn{5}{|l|}{$\mathrm{CU}>\mathrm{MCl}$ (within the medial temporal lobe only) } \\
\hline Right entorhinal cortex & 7 & 0.048 & 3.76 & {$[30,-10,-32]$} \\
\hline Left entorhinal cortex & 69 & 0.013 & 4.17 & {$[-28,-12,-34]$} \\
\hline
\end{tabular}

$K=$ number of voxels. Coordinates referenced to MNI space

Findings for $\mathrm{CU}>\mathrm{AD}$ and $\mathrm{MCl}>\mathrm{AD}$ are significant across the entire brain at the voxel level $p<.05 \mathrm{FWE}$-corrected. Findings for $\mathrm{CU}>\mathrm{MCl}$ are significant at $p<.05$ using small volume correction of MTL

those taking $(n=17)$ and those not taking $(n=15)$ memantine in any core ROI ( $p$ s > .38 for all comparisons).

Finally, we examined the potential effect of antidepressant treatment on 2FA binding in each of the diagnostic groups. For all ROIs and all diagnostic groups, there were no significant differences between those taking and those not taking antidepressant medication in any core ROI ( $p s>.14$ for all comparisons). Similarly, an overall
MANOVA that included antidepressants as a covariate did not change the effect of the diagnostic group on 2FA binding in the six core ROIs.

\section{Age effects}

We examined the effect of age on regional 2FA binding in the core ROIs in each diagnosis group. Within the $\mathrm{AD}$ group, there was a significant negative correlation 


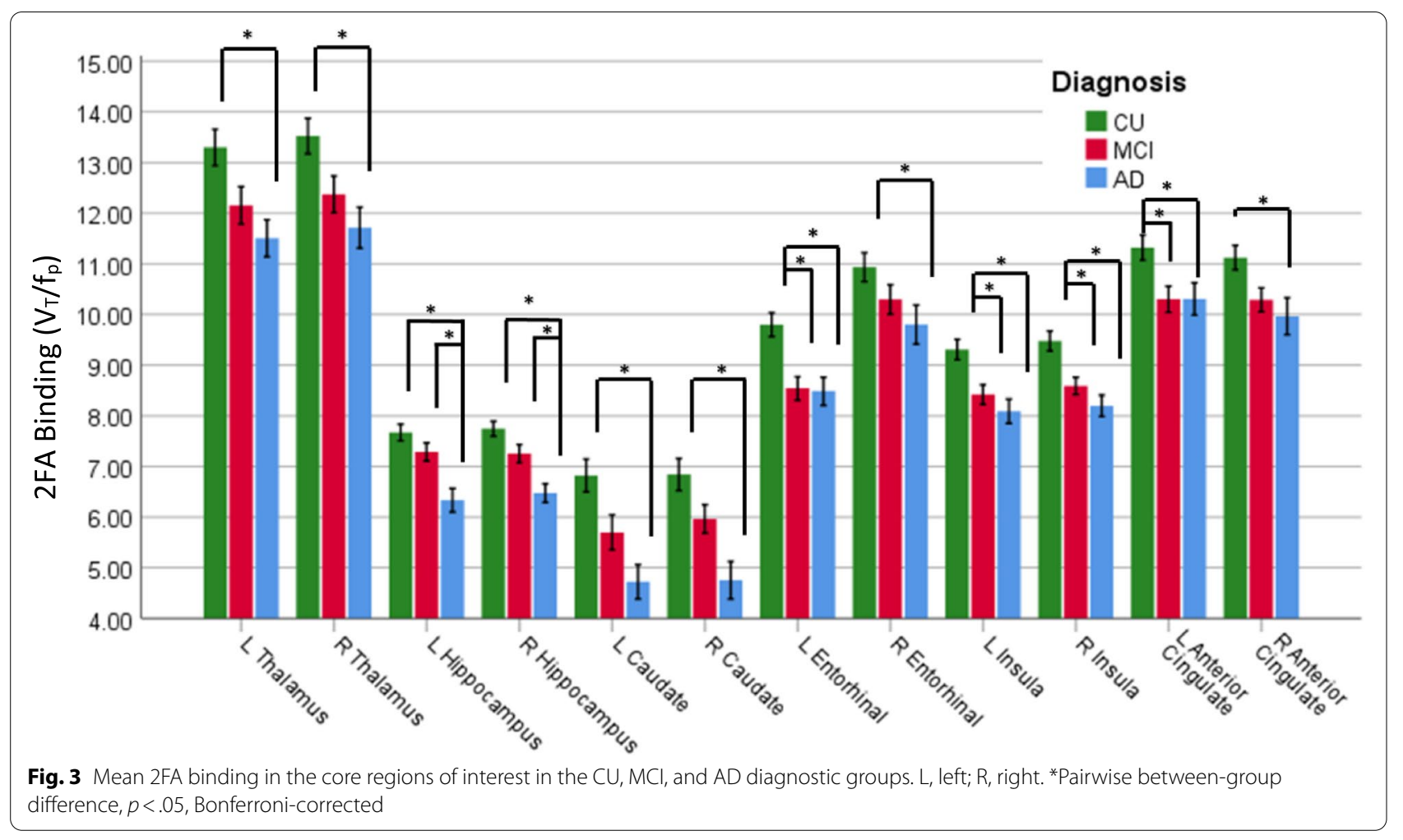

Table 4 Mean (SD) 2FA binding $\left(V_{T} / f_{p}\right)$ within the AD and $\mathrm{MCl}$ groups, for those on and off AChEl medication

\begin{tabular}{|c|c|c|c|c|}
\hline \multirow[t]{2}{*}{ Variable } & \multicolumn{2}{|l|}{$\mathrm{MCl}$} & \multicolumn{2}{|l|}{$A D$} \\
\hline & Off ${ }^{\mathrm{a} A C h E I}(n=20)$ & $\mathrm{On}^{\mathrm{a}} \mathrm{AChEI}(n=8)$ & Off AChEl $(n=9)$ & On AChEI $(n=23)$ \\
\hline L thalamus & $12.25(1.76)$ & $11.91(2.50)$ & $12.96(1.57)^{b}$ & $10.94(1.98)$ \\
\hline R thalamus & $12.42(1.64)$ & $12.28(2.62)$ & $13.12(1.53)^{b}$ & $11.17(2.34)$ \\
\hline L hippocampus & $7.15(.83)$ & $7.63(1.20)$ & $7.50(.84)^{\mathrm{b}}$ & $5.88(1.19)$ \\
\hline R hippocampus & $7.18(.80)$ & $7.44(1.30)$ & $7.34(.82)^{\mathrm{b}}$ & $6.14(.93)$ \\
\hline L caudate & $5.92(1.62)$ & $5.16(2.28)$ & $5.40(1.85)$ & $4.46(1.91)$ \\
\hline R caudate & $6.15(1.52)$ & $5.50(1.39)$ & $5.90(1.64)$ & $4.31(2.11)$ \\
\hline L entorhinal & $8.55(1.22)$ & $8.51(1.28)$ & $8.51(.87)$ & $8.48(1.77)$ \\
\hline Rentorhinal & $10.21(1.35)$ & $10.51(2.01)$ & $10.13(1.11)$ & $9.67(2.48)$ \\
\hline L insula & $8.22(.95)$ & $8.93(1.01)$ & $8.67(1.16)$ & $7.87(1.39)$ \\
\hline R insula & $8.44(.80)$ & $8.95(1.07)$ & $8.72(1.38)$ & $8.00(1.05)$ \\
\hline $\mathrm{L}$ anterior cingulate & $10.17(1.20)$ & $10.63(1.76)$ & $10.71(1.43)$ & $10.15(1.93)$ \\
\hline R anterior cingulate & $10.22(1.15)$ & $10.47(1.55)$ & $10.70(1.43)$ & $9.68(2.22)$ \\
\hline
\end{tabular}

a Off and on refers to the current use of cholinesterase inhibitor medication

${ }^{\mathrm{b}}$ Significant difference within the diagnostic group, $p<.05$

between age and 2FA binding in the bilateral hippocampus, left entorhinal cortex, bilateral insula, right anterior cingulate, and left caudate $(r(30)=-.39-.71$, $p=.000005-.029$ for each relationship). Within the MCI group, age was negatively correlated with binding in the right caudate $(r(26)=-.41, p=.03)$. Within the $\mathrm{CU}$ group, age was negatively correlated with 2FA binding in all core ROIs in each hemisphere (e.g., for right hippocampus, $r=-.50, p=.001 ; r s=-.33-.59$, $p s=.00004-.033$ for each relationship). As an example, the scatterplot for the relationship between age and 2FA binding in the right anterior cingulate is shown in Fig. 4. 


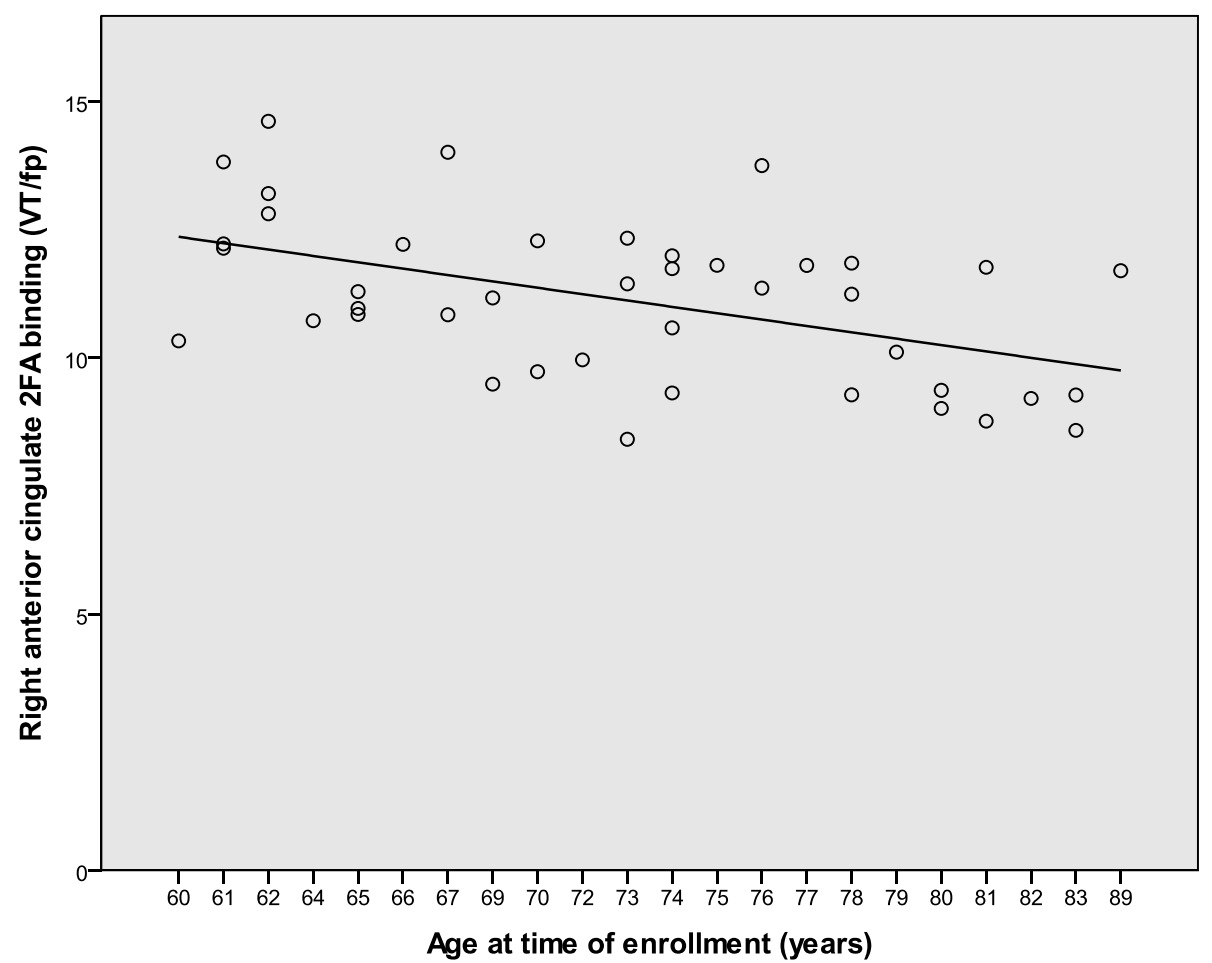

Fig. 4 Exemplar scatterplot of the negative association between age and 2FA binding in right anterior cingulate in the CU group

Across all study participants, age was correlated with diagnosis group membership $(r(100)=-.37, p=.00014$ with $\mathrm{AD}=1, \mathrm{MCI}=2$, and $\mathrm{CU}=3$ ). To reduce the impact of multicollinearity, the MANOVA was repeated while covarying for age to specifically examine the 2FA binding differences between the MCI and CU groups, as the AD participants were significantly older on average. This analysis, controlling for age, revealed lower 2FA binding in the MCI group compared to the $\mathrm{CU}$ group in the left entorhinal cortex and bilateral insula (post hoc pairwise comparison, $p=.001-.009$, Bonferroni-corrected; $n=28$ for MCI, $n=42$ for CU).

\section{Association between ROI 2FA binding and cognition}

Across all participants, the Attention average score (ATT) was correlated with 2FA binding in the bilateral hippocampus, insula, thalamus, caudate, and right anterior cingulate $(r(91)=.23-.34, p=.001-.03)$. The Immediate Recall (IR) average score was similarly associated with binding in the bilateral hippocampus, insula, caudate, and left entorhinal cortex $(r(97)=.21-.30$, $p=.003-.035$ for each relationship). The Delayed Recall (DR) average score was associated with binding in the bilateral hippocampus, insula, thalamus, caudate, and left entorhinal cortex $(r(94)=.24-.39, p=.00009-.042$ for each relationship).
Because cognitive assessment scores in the $\mathrm{AD}$ group showed floor effects, we repeated the analysis in the combined sample of CU and MCI $(n=68)$. For ATT, correlations were similar to the full sample, although the relationship with 2FA binding in the thalamus was no longer significant and the relationship with the left entorhinal cortex became significant. IR was not significantly correlated with any ROI ( $p$ s $>.18)$. DR was associated with the left caudate and left entorhinal cortex $(r(63)=.25-.35, p=.003-.038$ for each relationship). Covarying for the use of AChEI medication in the analysis of the combined $\mathrm{CU}$ and $\mathrm{MCI}$ groups did not substantially change the correlations for ATT or IR, while the relationship between DR and binding in the left caudate was no longer significant. Similarly, when covarying for age, IR and DR associations were unchanged, while ATT was positively associated with binding in the bilateral hippocampus and insula, right anterior cingulate, and right caudate.

Finally, we explored whether the inclusion of hippocampal volume in the model would alter the observed relationships between cognitive scores and regional 2FA binding. Of note, there were significant differences in the hippocampal volume between the groups, such that $\mathrm{AD}$ had lower volume than $\mathrm{CU}$ and MCI (see Table 1, $p s<.001)$. There was a marginal difference between $\mathrm{CU}$ 
and MCI (mean difference $=.0004, p=.06$ ). Within the combined sample of $\mathrm{CU}$ and MCI participants and controlling for hippocampal volume, ATT was associated with 2FA binding in the bilateral hippocampus, insula, and right anterior cingulate $(r(63)=.26-.35, p=.004-$ .038 for each relationship). There were no significant associations between IR and 2FA binding in any ROI. DR was positively associated with binding in the left entorhinal cortex $(r=.31, p=.01)$.

\section{Discussion}

The results of the whole-brain analysis in this study demonstrated lower levels of $\mathrm{nAChR}$ binding in $\mathrm{AD}$ dementia compared to cognitively unimpaired older adults in specific limbic and subcortical brain regions: hippocampus, entorhinal cortex, insula, anterior cingulate, thalamus, and caudate/anterior putamen. The complementary ROI analysis of select brain structures generally corroborated these findings and showed that $\mathrm{nAChR}$ binding was lower in $\mathrm{AD}$ by as much as $30 \%$ in the bilateral caudate and $16-18 \%$ in the bilateral hippocampus, with smaller reductions in other regions. Regional receptor binding in MCI participants was midway between binding levels in cognitively unimpaired and AD participants. In pairwise comparisons, MCI participants had lower binding than CU participants in the entorhinal cortex, as well as lower binding in the insula and left anterior cingulate in the $\mathrm{ROI}$ analysis. $\mathrm{AD}$ participants had lower binding than those with $\mathrm{MCI}$ in the bilateral hippocampus.

While this study was cross-sectional and cannot address longitudinal change within individuals, the results suggest that the number or binding affinity of nicotinic cholinergic receptors declines initially in the entorhinal cortex and other limbic structures as cognitive deficits appear in the AD process. The vulnerability of the entorhinal cortex to early cholinergic receptor loss may be related to its prominent functional connection to the basal forebrain cell groups [4]. Neurodegeneration in the nucleus basalis of Meynert (NbM) occurs early in the $\mathrm{AD}$ process and may precede entorhinal pathology. For example, smaller $\mathrm{NbM}$ volume was shown to predict greater degeneration in entorhinal and perirhinal cortices over time, and medial temporal lobe degeneration followed [12]. Similarly, in cognitively unimpaired older adults with cerebrospinal fluid evidence of cortical beta-amyloid, basal forebrain atrophy occurred prior to entorhinal cortex volume loss, which became apparent when cognitive deficits emerged [26]. The functional relationship between basal forebrain and medial temporal lobe structures was also supported by the observation that hippocampal vesicular acetylcholine transporter binding on PET imaging was lower in basal forebrain knockout mice than in wild-type mice [56]. Overall, prior findings and the results of our study support the early involvement of entorhinal pathology in the AD process, and other recent studies suggest that such pathology may be a consequence of basal forebrain degeneration that disrupts entorhinal cholinergic receptors with adverse cognitive consequences. The role of cholinergic receptors within the entorhinal cortex specifically is supported by our finding that deficits in the delayed recall were associated with lower 2FA binding in the left entorhinal cortex in the group of cognitively healthy and MCI participants. This finding persisted with control for the effect of hippocampal volume.

Our study also found that preserved cholinergic receptor binding in the hippocampus distinguished the MCI group from those with AD dementia. While medial temporal cortex structures may be susceptible to early cholinergic receptor decline in the $\mathrm{AD}$ process, continued loss of cholinergic receptor density or binding affinity in the hippocampus may contribute to cognitive and functional decline in the progression to $\mathrm{AD}$ dementia. The later and enduring impact of hippocampal cholinergic dysfunction may be due to its afferent input from the medial septum and vertical limb of the diagonal band of Broca in the basal forebrain, rather than from the nbM which is affected first in AD degeneration $[4,57]$.

2FA binding in AD participants taking acetylcholinesterase inhibitor medication was $15-20 \%$ lower in the hippocampus and thalamus than that among those not taking AChEI medication. Lower 2FA binding may be due to the competitive inhibition of radiotracer binding at the $\alpha 4 \beta 2$ receptor site as a consequence of higher synaptic acetylcholine levels in those taking this medication [58, 59]. However, chronic treatment with AChEI medication may alter the receptor binding affinity over time and lead to lower 2FA activity via a mechanism other than local neurotransmitter competition. Moreover, clinical benefit with AChEI medication may also be due to effects beyond increased synaptic acetylcholine, such as reduced amyloid toxicity or inflammation. In fact, a 2FA PET neuroimaging study found that cognitive improvement with galantamine treatment was not associated with a change in $\alpha 4 \beta 2$ receptor availability with treatment [60]. Additional work is needed to better understand the impact of altered cholinergic receptor binding at the molecular, cellular, and neural system levels and the response to pro-cholinergic treatments. While the limited sample size and non-random decisions to treat $\mathrm{AD}$ participants with AChEI medication in our study limit the conclusions that can be drawn, the effect of treatment on receptors in the hippocampus and thalamus suggests that these structures may play a distinct mechanistic role in cholinergic treatments. Cholinergic receptor imaging may aid effective drug development to 
alter $\mathrm{AD}$ progression or improve cognitive symptoms by demonstrating cholinoceptive target engagement as well as longitudinal treatment effects linked to cognitive stabilization or improvement.

Interestingly, the results of this study revealed a significant effect of age on nAChR binding in each of the diagnostic groups. In particular, within the cognitively unimpaired older adults, greater age was associated with lower 2FA binding in each of the brain regions that were also affected in AD. Age accounted for as much as 35\% of the variance in 2FA binding in this group. This finding suggests that nicotinic receptor density may decline steadily in cognitively healthy adults after age 60 years, although this requires confirmation in a longitudinal study. Similar to our result, Sihver et al. [61] demonstrated lower nAChR binding with age in the medial temporal cortex in healthy elderly participants, and Lagarde et al. [62] found fewer nAChR binding sites in the overall cortical gray matter in older healthy adults compared to younger healthy adults. However, other studies have shown mixed findings regarding cholinergic system decline with age [63]. If nicotinic cholinergic receptor density or affinity declines with age, as suggested by our study, it potentially represents a key mechanism or correlate of other important processes that drive mild memory and other cognitive difficulties that develop with age in healthy older adults. Such age-related cholinergic neuroreceptor alterations may also contribute to later-life vulnerability to superimposed $\mathrm{AD}$ pathophysiologies or those of other neurodegenerative disorders. Interventions to preserve cholinergic tone in later life may reduce such vulnerability.

The results of this study that included the largest $\mathrm{CU}$, $\mathrm{MCI}$, and $\mathrm{AD}$ samples studied to date in cholinergic imaging studies are consistent with prior neuroimaging work demonstrating lower cholinergic receptor binding in $\mathrm{AD}[33,34,38,62,64]$. However, the binding levels in $\mathrm{MCI}$, the specific brain regions affected in either $\mathrm{AD}$ or $\mathrm{MCI}$, and the relationships with cognition have been inconsistent across studies. The current study adds to the evidence that cholinergic receptor alterations occur in the medial temporal cortex and other limbic regions early in the degenerative process. The study also reveals that the extent of cholinergic receptor binding loss in these regions is modestly associated with a decline in cognitive measures of attention, immediate memory, and delayed memory across the entire group studied. In the subgroup of $\mathrm{CU}$ and MCI participants, relationships were strongest between 2FA binding and measures of attention that valued processing speed. Thus, there appears to be an early clinical impact of mild cholinergic receptor dysfunction, most prominently in the domain of attention. Associations between individual cognitive domains and
2FA binding were generally independent of hippocampal volume, indicating that lower neuroreceptor density or affinity contributed to the decline in attention and memory beyond the consequence of hippocampal cell loss. However, concurrent effects or interactions with other pathologies not measured in this study cannot be ruled out.

While this study measured binding at $\alpha 4 \beta 2$ nicotinic receptors specifically, other cholinergic receptor subtypes such as $\alpha 7$ nicotinic and M1-M5 muscarinic are also involved in healthy cognition and its decline in degenerative conditions. These additional receptor subtypes contribute to attention, memory, and hippocampal circuit integrity; have bidirectional relationships with other neuropathologies of $\mathrm{AD}$; and are considered potential treatment targets $[1,65,66]$. In concert with $\alpha 4 \beta 2$ receptors, the integrity and function of other cholinergic receptor subtypes and their collective effects on additional neurotransmitter systems are relevant to the cholinergic hypothesis of $\mathrm{AD}$.

How these neuroreceptor alterations are linked to traditional pathologies of $\mathrm{AD}$ such as $\beta$-amyloid and phosphorylated tau in the pathogenic cascade and expression of clinical symptoms of AD remains unclear. Current key issues include the specific sequence of pathophysiologic events in $\mathrm{AD}$, the time course of the sequence, and the critical interactions among etiologic factors in the transition from healthy aging to clinical AD. Because this study did not assess for the presence of $\beta$-amyloid, phospho- or total tau, neuroinflammatory alterations, or microvasculature changes, such relationships cannot be addressed. However, the results indicate that reduced cholinergic receptor binding occurs as part of the aging process, at least after age 60, and may contribute to AD vulnerability or may be a specific early AD pathology. However, we cannot rule out the presence of $\beta$-amyloid or other pathologies in the elderly $\mathrm{CU}$ participants in this study. Another research indicates that (1) $\beta$-amyloid deposition and abnormal tau processing occur very early in the $\mathrm{AD}$ continuum $[67,68]$; (2) elevated CSF $p$-tau/ $\beta$-amyloid ratio may drive longitudinal atrophy of $\mathrm{nbM}$ and subsequent volume loss in the entorhinal cortex [12], potentially via reduced cholinergic tone; (3) the $\mathrm{Ch} 4$ region of the basal forebrain shows a very early accumulation of phosphorylated tau [4]; and (4) early $\beta$-amyloid deposition may contribute to basal forebrain degeneration due to the structure's high sensitivity to amyloid-related loss of trophic factors [69]. Thus, while the decline in limbic nicotinic cholinergic receptor binding may be an early primary event in the $\mathrm{AD}$ process, other pathologies also emerge early and there are prominent bidirectional interactions. Longitudinal studies that assess several candidate pathologies, including cholinergic alterations, 
over an extended time period are needed to better define the path that leads to the cognitive and neuropsychiatric symptoms of clinical AD and to help identify intervention targets.

This study addressed cholinergic receptor deficits in AD specifically, but there are also cholinergic disturbances in other neurodegenerative conditions, such as Parkinson's disease (PD) and dementia with Lewy bodies (DLB). A small number of comparative postmortem studies suggest that differences in cholinergic disturbances may distinguish these neurodegenerative conditions. For instance, loss of choline acetyltransferase appears to be greater in DLB compared to AD [70], especially among DLB patients exhibiting hallucinations [71]. Cholinergic neuronal loss is also more severe in the basal ganglia in PD and DLB compared to AD [72], and there is a greater loss of nicotinic receptor binding in the striatum in PD compared to DLB and AD [73]. Yet, a study that employed I-5-Iodo-3-[2(S)-2-azetidinylmethoxy] pyridine single-photon emission computed tomography (SPECT) imaging found that regional $\alpha 4 \beta 2$ cholinergic deficits in a pooled AD/DLB sample correlated with the subsequent decline in executive function [29]. The effect was similar in the two diagnostic groups, suggesting that relationships between cholinergic function and executive skills may be similar in the two disorders. Further research can address cholinergic system integrity and respective relationships with individual cognitive domains across neurodegenerative conditions.

\section{Limitations}

This study has several strengths, including a sample sufficiently large to detect moderate group differences in regional cholinergic receptor binding, inclusion of carefully characterized participants, and use of structural MRI in addition to 2FA imaging to assess binding in anatomically defined brain regions and to allow the inclusion of hippocampal volume in evaluating the relationships with cognitive skills. The study also has several limitations. Amyloid biomarkers were not measured, so we were unable to apply an $\mathrm{A} / \mathrm{T} / \mathrm{N}$ framework to the sample. However, the lower hippocampal volumes measured in the study were consistent with those expected in $\mathrm{MCI}$ due to $\mathrm{AD}$ and in $\mathrm{AD}$ dementia, and NIA/AA clinical Alzheimer's disease criteria were applied by experienced investigators using detailed neuropsychological assessments. Nonetheless, we cannot assume that the MCI and AD participants had elevated cortical amyloid levels, and the results of the study may also apply to those with cognitive deficits resulting from other etiologies. Also, cerebrovascular changes were not included in the models, which could confound the findings. However, structural neuroimaging studies were used to exclude any participant with substantial small vessel cerebrovascular disease or cortical infarct. The MCI and AD groups included predominantly men, and thus, we were unable to assess the effect of sex or a sex $x$ diagnosis interaction. Finally, the modest sample size limited our ability to fully dissect the effects of older age in the AD group, medication treatment, or binding in specific brain regions on the magnitude of cholinergic receptor binding across the groups or relationships with cognitive skills.

\section{Conclusions}

Overall, the results of this study support a more contemporary view of the "cholinergic hypothesis" of $\mathrm{AD}$, demonstrating reduced cholinoceptive binding in specific limbic and subcortical regions in $\mathrm{AD}$ dementia that was also present in some brain regions at the $\mathrm{MCI}$ phase. Reduced binding was associated with deficits in attention and recent memory in the overall sample and with lower attention skills in the combined group of cognitively healthy and MCI participants. Among cognitively unimpaired older adults, cholinergic receptor binding appears to decline with age and may represent a mechanism for cognitive aging or confer vulnerability to additional neurodegenerative processes in later life. Further studies can help refine the understanding of these relationships, can reveal regional changes over time and their links to other pathologies, and may help identify opportunities for symptomatic or disease-modifying AD treatments.

\section{Abbreviations \\ AD: Alzheimer's disease; MCl: Mild cognitive impairment; CU: Cognitively unimpaired; AChEl: Cholinesterase inhibitor medication; 2FA: 2-[ $\left[{ }^{18} \mathrm{~F}\right]$ fluoro-3- (2(S)azetidinylmethoxy)pyridine; ATT: Attention average index; IR: Immediate recall average index; DR: Delayed recall average index.}

\section{Acknowledgements}

The authors gratefully acknowledge the guidance and expert technical assistance by Arthur Brody, Mark Mandelkern, Joseph Veliz, Josephine Ribe, Stacy Wilkins, Dylan Harwood, Theresa Narvaez, Hannah Riskin-Jones, Timothy Ando, and Kevin Juarez.

\section{Authors' contributions}

DLS designed the study; made substantial contributions to the acquisition, analysis, and interpretation of the data; and drafted and revised significant sections of the manuscript. ACL made substantial contributions to the analysis and interpretation of the data and drafted and revised the significant sections of the manuscript. HLG made substantial contributions to the acquisition, analysis, and interpretation of the data. BCY made substantial contributions to the interpretation of the data and drafted and revised significant sections of the manuscript. RJM contributed significantly to the study design; made substantial contributions to the acquisition, analysis, and interpretation of the data; and drafted and revised significant sections of the manuscript. All authors have approved the submitted final version of the manuscript, agree to be personally accountable for his/her contributions, and agree to ensure that questions related to the accuracy or integrity of any part of the work are appropriately investigated and resolved and that the resolution is documented in the literature. 


\section{Funding}

Supported by the US Department of Veterans Affairs (DLS: Merit Review Award CX-000409; RJM: Merit Review Award CX-001128; BCY: Career Development Award CX-001884) and the National Institute on Aging (Alzheimer's Disease Research Center Award, P30AG066519, to the University of California, Irvine; and T32AG000037 to ACL). Funding bodies were not involved in the design of the study; collection, analysis, or interpretation of data; or writing of the manuscript.

\section{Availability of data and materials}

Data composites that support the findings of this study are available from the corresponding author upon reasonable request and institutional approval.

\section{Declarations}

\section{Ethics approval and consent to participate}

All study and consent procedures were reviewed and approved by the VA Greater Los Angeles Healthcare System institutional review board and are consistent with the principles of the Declaration of Helsinki.

\section{Consent for publication}

\section{Not applicable.}

\section{Competing interests}

DLS has received research support from NIH and Eisai; has participated as a paid member of a DSMB or adjudication committee with Acadia, Avanir, Janssen, and Otsuka; and has received consulting fees from Avanir and NovoNordisk (all unrelated to cholinergic brain systems). The other authors declare that they have no competing interests.

\section{Author details}

${ }^{1}$ Psychiatry/Mental Health Service, VA Greater Los Angeles Healthcare System, Los Angeles, CA, USA. ${ }^{2}$ Department of Psychiatry and Human Behavior, School of Medicine, and Institute for Memory Impairments and Neurological Disorders (UCI MIND), University of California, Irvine, Irvine, CA, USA. ${ }^{3}$ Department of Family Medicine, USC Keck School of Medicine, Alhambra, CA, USA. ${ }^{4}$ Biomedical Engineering Department, Carnegie Mellon University, Pittsburgh, PA, USA. ${ }^{5}$ Department of Psychiatry and Biobehavioral Sciences, David Geffen School of Medicine at UCLA, Los Angeles, CA, USA.

Received: 19 July 2021 Accepted: 21 December 2021

Published online: 07 February 2022

\section{References}

1. Bekdash RA. The cholinergic system, the adrenergic system and the neuropathology of Alzheimer's disease. Int J Mol Sci. 2021;22:1273.

2. Dumas JA, Newhouse PA. The cholinergic hypothesis of cognitive aging revisited again: cholinergic functional compensation. Pharmacol Biochem Behav. 2011;99:254-61.

3. Geula C, Nagykery N, Nicholas A, Wu CK. Cholinergic neuronal and axonal abnormalities are present early in aging and in Alzheimer disease. J Neuropathol Exp Neurol. 2008;67:309-18.

4. Mesulam MM. Cholinergic circuitry of the human nucleus basalis and its fate in Alzheimer's disease. J Comp Neurol. 2013;521:4124-44.

5. Schliebs R, Arendt T. The cholinergic system in aging and neuronal degeneration. Behav Brain Res. 2011;221:555-63.

6. Hampel H, Mesulam M-M, Cuello AC, Farlow MR, Giacobini E, Grossberg GT, et al. The cholinergic system in the pathophysiology and treatment of Alzheimer's disease. Brain. 2018;141:1917-33.

7. Whitehouse PJ, Price DL, Clark AW, Coyle JT, DeLong MR. Alzheimer disease: evidence for selective loss of cholinergic neurons in the nucleus basalis. Ann Neurol. 1981;10:122-6.

8. Mesulam M. A horseradish peroxidase method for the identification of the efferents of acetyl cholinesterase-containing neurons. J Histochem Cytochem. 1976;24:1281-5.
9. Bowen DM, Smith CB, White P, Davison AN. Neurotransmitter-related enzymes and indices of hypoxia in senile dementia and other abiotrophies. Brain. 1976;99:459-96.

10. Grothe $M$, Heinsen $H$, Teipel SJ. Atrophy of the cholinergic basal forebrain over the adult age range and in early stages of Alzheimer's disease. Biol Psychiatry. 2012;71:805-13.

11. Gil-Bea FJ, Gerenu G, Aisa B, Kirazov LP, Schliebs R, Ramirez MJ. Cholinergic denervation exacerbates amyloid pathology and induces hippocampal atrophy in Tg2576 mice. Neurobiol Dis. 2012:48:439-46.

12. Fernández-Cabello S, Kronbichler M, Van Dijk KRA, Goodman JA, Spreng $\mathrm{RN}$, Schmitz TW. Basal forebrain volume reliably predicts the cortical spread of Alzheimer's degeneration. Brain. 2020;143:993-1009.

13. Ballinger EC, Ananth M, Talmage DA, Role LW. Basal forebrain cholinergic circuits and signaling in cognition and cognitive decline. Neuron. 2016;91:1199-218.

14. Newhouse P, Kellar K, Aisen P, White H, Wesnes K, Coderre E, et al. Nicotine treatment of mild cognitive impairment: a 6-month double-blind pilot clinical trial. Neurology. 2012;78:91-101.

15. Schliebs R, Arendt T. The significance of the cholinergic system in the brain during aging and in Alzheimer's disease. J Neural Transm. 2006;113:1625-44.

16. Mori F, Lai CC, Fusi F, Giacobini E. Cholinesterase inhibitors increase secretion of APPs in rat brain cortex. Neuroreport. 1995;6:633-6.

17. Nitsch RM, Slack BE, Wurtman RJ, Growdon JH. Release of Alzheimer amyloid precursor derivatives stimulated by activation of muscarinic acetylcholine receptors. Science. 1992;258:304-7.

18. Kalkman $\mathrm{HO}$, Feuerbach D. Modulatory effects of a7 nAChRs on the immune system and its relevance for CNS disorders. Cell Mol Life Sci. 2016:73:2511-30.

19. Roberts JP, Stokoe SA, Sathler MF, Nichols RA, Kim S. Selective co-activation of a7- and a4 $\beta 2$-nicotinic acetylcholine receptors reverses beta-amyloid-induced synaptic dysfunction. J Biol Chem. 2021:296:100402.

20. Cantero JL, Atienza M, Lage C, Zaborszky L, Vilaplana E, Lopez-Garcia S, et al. Atrophy of basal forebrain initiates with tau pathology in individuals at risk for Alzheimer's disease. Cereb Cortex. 2019;30:2083-98.

21. Härtig W, Saul A, Kacza J, Grosche J, Goldhammer S, Michalski D, et al. Immunolesion-induced loss of cholinergic projection neurones promotes $\beta$-amyloidosis and tau hyperphosphorylation in the hippocampus of triple-transgenic mice. Neuropathol Appl Neurobiol. 2014;40:106-20.

22. Mesulam M, Shaw P, Mash D, Weintraub S. Cholinergic nucleus basalis tauopathy emerges early in the aging-MCl-AD continuum. Ann Neurol. 2004;55:815-28.

23. Rubio A, Perez M, Avila J. Acetylcholine receptors and tau phosphorylation. Curr Mol Med. 2006:6:423-8.

24. Reale M, Costantini E. Cholinergic modulation of the immune system in neuroinflammatory diseases. Diseases. 2021;9:29.

25. Kolisnyk B, Al-Onaizi M, Soreq L, Barbash S, Bekenstein U, Haberman N, et al. Cholinergic surveillance over hippocampal RNA metabolism and Alzheimer's-like pathology. Cereb Cortex. 2017;27:3553-67.

26. SchmitzTW, Spreng RN. Basal forebrain degeneration precedes and predicts the cortical spread of Alzheimer's pathology. Nat Commun. 2016;7:13249

27. Bott J-B, Héraud C, Cosquer B, Herbeaux K, Aubert J, Sartori M, et al. APOE-sensitive cholinergic sprouting compensates for hippocampal dysfunctions due to reduced entorhinal input. J Neurosci. 2016;36:10472-86.

28. Cheng YJ, Lin CH, Lane HY. Involvement of cholinergic, adrenergic, and glutamatergic network modulation with cognitive dysfunction in Alzheimer's disease. Int J Mol Sci. 2021:22(5):2283.

29. Colloby SJ, Perry EK, Pakrasi S, Pimlott SL, Wyper DJ, McKeith IG, et al. Nicotinic ${ }^{123}$ |-5IA-85380 single photon emission computed tomography as a predictor of cognitive progression in Alzheimer's disease and dementia with Lewy bodies. Am J Geriatr Psychiatry. 2010;18:86-90.

30. Ellis JR, Villemagne VL, Nathan PJ, Mulligan RS, Gong SJ, Chan JG, et al. Relationship between nicotinic receptors and cognitive function in early Alzheimer's disease: a 2-[(18)F]fluoro-A-85380 PET study. Neurobiol Learn Mem. 2008;90:404-12. 
31. Nordberg A, Lundqvist H, Hartvig P, Andersson J, Johansson M, Hellstrom-

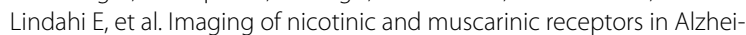
mer's disease: effect of tacrine treatment. Dement Geriatr Cogn Disord. 1997:8:78-84.

32. Okada H, Ouchi Y, Ogawa M, Futatsubashi M, Saito Y, Yoshikawa E, et al. Alterations in alpha4beta2 nicotinic receptors in cognitive decline in Alzheimer's aetiopathology. Brain. 2013;136:3004-17.

33. Sabri O, Kendziorra K, Wolf H, Gertz HJ, Brust P. Acetylcholine receptors in dementia and mild cognitive impairment. Eur J Nucl Med Mol Imaging. 2008;35(Suppl 1):S30-45.

34. Sabri O, Meyer PM, Gräf S, Hesse S, Wilke S, Becker G-A, et al. Cognitive correlates of a $4 \beta 2$ nicotinic acetylcholine receptors in mild Alzheimer's dementia. Brain. 2018;141:1840-54.

35. Brody AL, Mandelkern MA, London ED, Olmstead RE, Farahi J, Scheibal D, et al. Cigarette smoking saturates brain alpha 4 beta 2 nicotinic acetylcholine receptors. Arch Gen Psychiatry. 2006;63:907-15.

36. Kimes AS, Chefer SI, Matochik JA, Contoreggi CS, Vaupel DB, Stein EA, et al. Quantification of nicotinic acetylcholine receptors in the human brain with PET: bolus plus infusion administration of 2-[18F]F-A85380. Neuroimage. 2008:39:717-27.

37. Sorger D, Becker GA, Patt M, Schildan A, Grossmann U, Schliebs R, et al. Measurement of the alpha4beta2* nicotinic acetylcholine receptor ligand 2-[(18)F]fluoro-A-85380 and its metabolites in human blood during PET investigation: a methodological study. Nucl Med Biol. 2007;34:331-42.

38. Sultzer DL, Melrose RJ, Riskin-Jones H, Narvaez TA, Veliz J, Ando TK, et al. Cholinergic receptor binding in Alzheimer disease and healthy aging: assessment in vivo with positron emission tomography imaging. Am J Geriatr Psychiatry. 2017;25:342-53.

39. Lawton MP, Brody EM. Assessment of older people: self-maintaining and instrumental activities of daily living. Gerontologist. 1969;9:179-86.

40. McKhann GM, Knopman DS, Chertkow H, Hyman BT, Jack CR, Kawas CH, et al. The diagnosis of dementia due to Alzheimer's disease: recommendations from the National Institute on Aging-Alzheimer's Association workgroups on diagnostic guidelines for Alzheimer's disease. Alzheimers Dement. 2011;7:6.

41. Jack CR Jr, Bennett DA, Blennow K, Carrillo MC, Feldman HH, Frisoni GB, et al. A/T/N: an unbiased descriptive classification scheme for Alzheimer disease biomarkers. Neurology. 2016:87:539-47.

42. Fischl B, Salat DH, Busa E, Albert M, Dieterich M, Haselgrove C, et al. Whole brain segmentation: automated labeling of neuroanatomical structures in the human brain. Neuron. 2002;33:341-55.

43. Dolle F, Valette H, Bottlaender M, Hinnen F, Vaufrey F, Guenther I, et al. Synthesis of 2-(18F)fluoro-3-(2(S)-2-azetidinylmethoxy)pyridine, a highly potent radioligand for in vivo imaging central nicotinic acetylcholine receptors. J Labelled Cpd Radiopharm. 1998;41:451-63.

44. Brody AL, Mukhin AG, La Charite J, Ta K, Farahi J, Sugar CA, et al. Up-regulation of nicotinic acetylcholine receptors in menthol cigarette smokers. Int J Neuropsychopharmacol. 2013;16:957-66.

45. Brody AL, Mandelkern MA, Costello MR, Abrams AL, Scheibal D, Farahi J, et al. Brain nicotinic acetylcholine receptor occupancy: effect of smoking a denicotinized cigarette. Int J Neuropsychopharmacol. 2009;12:305-16.

46. Brody AL, Mandelkern MA, London ED, Khan AR, Kozman D, Costello MR, et al. Effect of secondhand smoke on occupancy of nicotinic acetylcholine receptors in brain. Arch Gen Psychiatry. 2011;68:953-60.

47. Brody AL, Mukhin AG, Stephanie S, Mamoun MS, Kozman M, Phuong J, et al. Treatment for tobacco dependence: effect on brain nicotinic acetylcholine receptor density. Neuropsychopharmacology. 2013;38:1548-56.

48. Chefer SI, London ED, Koren AO, Pavlova OA, Kurian V, Kimes AS, et al. Graphical analysis of 2-[18F]FA binding to nicotinic acetylcholine receptors in rhesus monkey brain. Synapse. 2003;48:25-34

49. Innis RB, Cunningham VJ, Delforge J, Fujita M, Gjedde A, Gunn RN, et al. Consensus nomenclature for in vivo imaging of reversibly binding radioligands. J Cereb Blood Flow Metab. 2007;27:1533-9.

50. Gonzalez-Escamilla G, Lange C, Teipel S, Buchert R, Grothe MJ. PETPVE12: an SPM toolbox for partial volume effects correction in brain PET - application to amyloid imaging with AV45-PET. Neuroimage. 2017;147:669-77.
51. Müller-Gärtner HW, Links JM, Prince JL, Bryan RN, McVeigh E, Leal JP, et al. Measurement of radiotracer concentration in brain gray matter using positron emission tomography: MRI-based correction for partial volume effects. J Cereb Blood Flow Metab. 1992;12:571-83.

52. Rousset OG, Ma Y, Evans AC. Correction for partial volume effects in PET: principle and validation. J Nucl Med. 1998;39:904-11.

53. Gaser C. Partial volume segmentation with adaptive maximum a posteriori (MAP) approach. Neurolmage. 2009;47:S121.

54. Desikan RS, Segonne F, Fischl B, Quinn BT, Dickerson BC, Blacker D, et al. An automated labeling system for subdividing the human cerebral cortex on MRI scans into gyral based regions of interest. Neuroimage. 2006;31:968-80.

55. Faul F, Erdfelder E, Lang A-G, Buchner A. G*Power 3: a flexible statistical power analysis program for the social, behavioral, and biomedical sciences. Behav Res Methods. 2007;39:175-91.

56. Schmitz TW. In vivo molecular imaging of cortical cholinergic denervation in preclinical Alzheimer's disease. In: Presented at the $15^{\text {th }}$ International Conference on Alzheimer's and Parkinson's Diseases and Related Neurological Disorders (AD/PD); 2021.

57. Tiernan CT, Mufson EJ, Kanaan NM, Counts SE. Tau oligomer pathology in nucleus basalis neurons during the progression of Alzheimer disease. J Neuropathol Exp Neurol. 2018;77:246-59.

58. Vallianatou T, Shariatgorji M, Nilsson A, Fridjonsdottir E, Källback P, Schintu N, et al. Molecular imaging identifies age-related attenuation of acetylcholine in retrosplenial cortex in response to acetylcholinesterase inhibition. Neuropsychopharmacology. 2019;44:2091-8.

59. Hillmer AT, Esterlis I, Gallezot JD, Bois F, Zheng MQ, Nabulsi N, et al. Imaging of cerebral $a 4 \beta 2^{*}$ nicotinic acetylcholine receptors with (-)-[(18)F]flubatine PET: implementation of bolus plus constant infusion and sensitivity to acetylcholine in human brain. Neuroimage. 2016;141:71-80.

60. Ellis JR, Nathan PJ, Villemagne VL, Mulligan RS, Saunder T, Young K, et al. Galantamine-induced improvements in cognitive function are not related to alterations in alpha(4)beta (2) nicotinic receptors in early Alzheimer's disease as measured in vivo by 2-[(18)F]fluoro-A-85380 PET. Psychopharmacology (Berl). 2009;202:79-91.

61. Sihver W, Gillberg PG, Svensson AL, Nordberg A. Autoradiographic comparison of $[3 \mathrm{H}]$ nicotine, $[3 \mathrm{H}]$ cytisine and $[3 \mathrm{H}]$ epibatidine binding in relation to vesicular acetylcholine transport sites in the temporal cortex in Alzheimer's disease. Neuroscience. 1999;94:685-96.

62. Lagarde J, Sarazin M, Chauvire V, Stankoff B, Kas A, Lacomblez L, et al. Cholinergic changes in aging and Alzheimer disease: an [18F]-F-A-85380 exploratory PET study. Alzheimer Dis Assoc Disord. 2017;31:8-12.

63. Decker MW. The effects of aging on hippocampal and cortical projections of the forebrain cholinergic system. Brain Res. 1987:434:423-38.

64. Kendziorra K, Wolf H, Meyer PM, Barthel H, Hesse S, Becker GA, et al. Decreased cerebral alpha4beta2* nicotinic acetylcholine receptor availability in patients with mild cognitive impairment and Alzheimer's disease assessed with positron emission tomography. Eur J Nucl Med Mol Imaging. 2011;38:515-25.

65. Bertrand D, Wallace TL. A review of the cholinergic system and therapeutic approaches to treat brain disorders. Curr Top Behav Neurosci. 2020:45:1-28.

66. Lebois EP, Thorn C, Edgerton JR, Popiolek M, Xi S. Muscarinic receptor subtype distribution in the central nervous system and relevance to aging and Alzheimer's disease. Neuropharmacology. 2018;136:362-73.

67. Hanseeuw BJ, Betensky RA, Jacobs HIL, Schultz AP, Sepulcre J, Becker JA, et al. Association of amyloid and tau with cognition in preclinical Alzheimer disease: a longitudinal study. JAMA Neurol. 2019;76:915-24

68. Barthélemy NR, Li Y, Joseph-Mathurin N, Gordon BA, Hassenstab J, Benzinger TLS, et al. A soluble phosphorylated tau signature links tau, amyloid and the evolution of stages of dominantly inherited Alzheimer's disease. Nat Med. 2020;26:398-407.

69. Pepeu G, Giovannini MG. The fate of the brain cholinergic neurons in neurodegenerative diseases. Brain Res. 2017;1670:173-84. 
70. Tiraboschi P, Hansen LA, Alford M, Merdes A, Masliah E, Thal LJ, et al. Early and widespread cholinergic losses differentiate dementia with Lewy bodies from Alzheimer disease. Arch Gen Psychiatry. 2002;59:946-51.

71. Perry EK, Marshall E, Kerwin J, Smith CJ, Jabeen S, Cheng AV, et al. Evidence of a monoaminergic-cholinergic imbalance related to visual hallucinations in Lewy body dementia. J Neurochem. 1990;55:1454-6.

72. Perry EK, Morris CM, Court JA, Cheng A, Fairbairn AF, McKeith IG, et al. Alteration in nicotine binding sites in Parkinson's disease, Lewy body dementia and Alzheimer's disease: possible index of early neuropathology. Neuroscience. 1995;64:385-95.

73. Perry E, Martin-Ruiz C, Lee M, Griffiths M, Johnson M, Piggott M, et al. Nicotinic receptor subtypes in human brain ageing, Alzheimer and Lewy body diseases. Eur J Pharmacol. 2000;393:215-22.

\section{Publisher's Note}

Springer Nature remains neutral with regard to jurisdictional claims in published maps and institutional affiliations.s

- fast, convenient online submission

- thorough peer review by experienced researchers in your field

- rapid publication on acceptance

- support for research data, including large and complex data types

- gold Open Access which fosters wider collaboration and increased citations

- maximum visibility for your research: over 100M website views per year

At BMC, research is always in progress.

Learn more biomedcentral.com/submissions 